\title{
Rearfoot disorders and conservative treatment: a narrative review
}

\author{
Yoo Jin Choo ${ }^{1}$, Chul Hyun Park ${ }^{2}$, Min Cheol Chang ${ }^{3}$ \\ ${ }^{1}$ Production R\&D Division Advanced Interdisciplinary Team, Medical Device Development Center, Daegu-Gyeongbuk Medical Innovation \\ Foundation, Deagu, Republic of Korea; ${ }^{2}$ Department of Orthopedic Surgery, ${ }^{3}$ Department of Rehabilitation Medicine, College of Medicine, \\ Yeungnam University, Daegu, Republic of Korea \\ Contributions: (I) Conception and design: YJ Choo; (II) Administrative support: MC Chang; (III) Provision of study materials or patients: YJ Choo; \\ (IV) Collection and assembly of data: All authors; (V) Data analysis and interpretation: All authors; (VI) Manuscript writing: All authors; (VII) Final \\ approval of manuscript: All authors. \\ Correspondence to: Min Cheol Chang, MD. Department of Physical Medicine and Rehabilitation, College of Medicine, Yeungnam University 317-1, \\ Daemyungdong, Namku, Taegu, 705-717, Republic of Korea. Email: wheel633@ynu.ac.kr.
}

\begin{abstract}
Rearfoot disorders are frequently encountered in clinical practice. We reviewed common rearfoot disorders and present conservative treatments, focusing on shoe modification and the application of insoles or orthoses. Achilles tendinopathy is caused by excessive mechanical loads on the gastrocnemius and soleus muscles. Heel lifts, rocker shoes, and the AirHeel Brace can be used to reduce symptoms. Haglund's deformity is an osseous prominence of the posterosuperior part of the calcaneus bone, the pain from which can be alleviated by reducing pressure on the affected area by appropriately modifying the back of the shoe to prevent contact with the lesion. The pain from retrocalcaneal bursitis can be controlled by lifting the heel and loosening the shoe counter. Plantar fasciitis causes plantar heel pain, and its orthotic treatments include the application of a heel cup, heel pad, heel wedge, Thomas heel, and night splint. Calcaneal stress fractures are generally caused by repetitive loads and occur mainly in sporting activities. Patellar tendon-bearing (PTB) orthoses are helpful in reducing the load on the calcaneal bone. Heel fat pad atrophy refers to the loss of the fat pad that absorbs shock in the heel. To reduce pain caused by heel fat pad atrophy, rocker soles, heel pads, and solid ankle cushion heels (SACHs) may be used. Tarsal tunnel syndrome is caused by compression of the tibial nerve within the tarsal tunnel and its symptoms can be managed by rocker soles, supporting medial arches, Thomas heels, and SACHs. Shoe modification or application of orthoses can be helpful for managing rearfoot pain. However, for the active and wide application of these conservative treatment methods, more clinical studies should be conducted.
\end{abstract}

Keywords: Conservative treatment; rearfoot disorder; insole; orthosis; shoes

Submitted Feb 19, 2020. Accepted for publication Jul 14, 2020.

doi: $10.21037 /$ apm-20-446

View this article at: http://dx.doi.org/10.21037/apm-20-446

\section{Introduction}

The foot is subdivided into the forefoot, midfoot, and rearfoot, comprising the 5 metatarsals and 14 phalanges; navicular, medial cuneiform, internal cuneiform, lateral cuneiform, and cuboid bones; and talus and calcaneus bones, respectively. Common disorders occurring in the rearfoot include Achilles tendinopathy, retrocalcaneal bursitis, plantar fasciitis, calcaneal stress fractures, heel fat pad atrophy, and tarsal tunnel syndrome. These rearfoot disorders cause pain in the area around the calcaneal bone, hindering patients' gait. Conservative treatments, including shoe modification, application of insoles or orthoses, oral medications, and steroid injections, are preferred for rearfoot disorders.

Herein, we summarize common rearfoot disorders and present conservative treatments with a focus on shoe modification and the application of insoles or orthoses. We present the following article in accordance with the NARRATIVE REVIEW reporting checklist (available at http://dx.doi.org/10.21037/apm-20-446). 


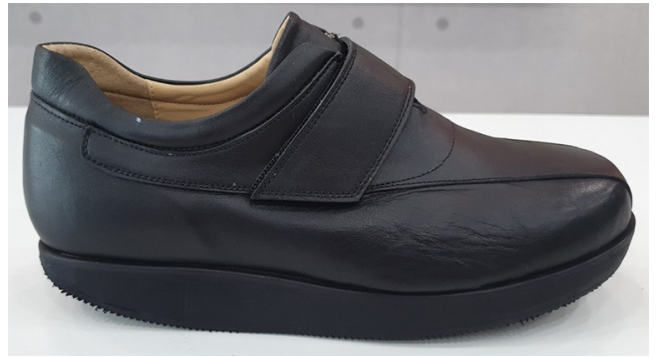

Figure 1 Rocker bottom shoe.

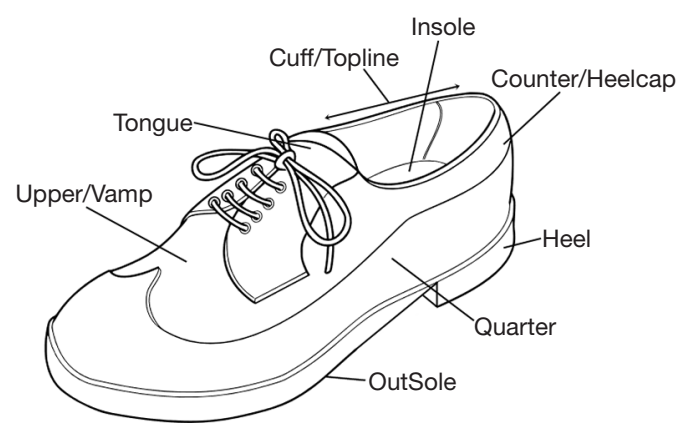

Figure 2 Shoe diagram.

\section{Rearfoot disorders}

\section{Achilles tendinopathy}

The Achilles tendon merges with the gastrocnemius and soleus muscles superiorly and inserts into the bottom of the calcaneus inferiorly (1). Achilles tendinopathy is a common overuse injury caused by excessive compression or mechanical loading of the gastrocnemius and soleus muscles $(1,2)$. It can be classified as mid-portion tendinopathy or insertional tendinopathy. Mid-portion tendinopathy involves pain occurring at 2 to $6 \mathrm{~cm}$ from the calcaneal insertion, and insertional tendinopathy involves pain occurring at the insertion of the Achilles tendon (2). Conservative treatments include rest, muscle strengthening exercises, manual therapy, shoe modifications, non-steroidal anti-inflammatory medications, low-level laser therapy, steroid injections, and topical glyceryl trinitrate patches $(3,4)$. Some shoe modification methods are effective in controlling pain related to Achilles tendinopathy. Heel lifts can reduce the strain on the Achilles tendon (5). Furthermore, rocker-bottom shoes (Figure 1) can reduce the load on the Achilles tendon because they reduce plantar flexion (6).
In 2012, Farris et al. (7) evaluated the effects of heel lifts on Achilles tendon force and strain during running and compared the effects of non-heel lift, 12-mm heel lift, and $18-\mathrm{mm}$ heel lift on 10 subjects during running. They found that peak Achilles tendon strain and force were lowest with an 18-mm heel lift. In 2015, Sobhani et al. (6) investigated the effect of rocker shoes relative to standard shoes and reported a significant decrease in the plantar flexion movement when walking or running in rocker shoes.

Furthermore, the AirHeel Brace, specially designed to treat Achilles tendinopathy, was reported to effectively control symptoms. The manufacturers suggest that the two interconnected air cells positioned under the heel and above the calcaneus apply pulsating compression with every step, reducing discomfort and enhancing circulation. In 2007, Petersen et al. (8) reported that the application of the AirHeel Brace in 31 patients with chronic Achilles tendinopathy reduced the patients' pain by $43 \%$ after 6 weeks.

\section{Haglund's deformity}

Haglund's deformity is an osseous prominence of the posterosuperior part of the calcaneus bone, resulting in pain and swelling in the posterior heel $(9,10)$. The etiology of Haglund's deformity is unclear, but several possible causes, such as a tight Achilles tendon, altered biomechanics of the foot joints, high foot arch, heredity, and tight or poorly fitting shoes, have been suggested (11). Pain presents in the posterior heel and is aggravated by climbing stairs or moving the heel repeatedly and beginning to walk after rest. This condition can be unilateral or bilateral $(11,12)$. In patients with Haglund's deformity, a bump is observed on the posterior heel, and a bony prominence at the posterosuperior part of the calcaneal tuberosity is found on $\mathrm{X}$-ray examination and magnetic resonance imaging $(1,10,11)$. It was reported that $25 \%$ of patients with insertional Achilles tendinopathy have Haglund's deformity (13). The conservative treatment of Haglund's deformity includes anti-inflammatory/analgesic medication, physical therapy, and reducing pressure on the affected area with shoe modifications. The shoe modifications that can be applied are as follows: (I) wearing shoes where the upper trim line of the quarter is under or over the bone protrusion; (II) placing heel lifts in shoes to bring the heel up, which can avoid friction between the deformity and counter of the shoe (Figure 2); (III) applying a tongue pad or Achilles heel pad within the heel counter of the shoe to 


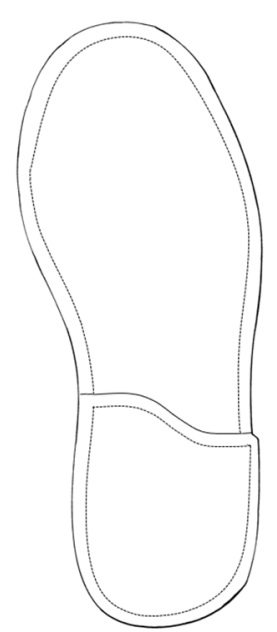

Figure 3 Thomas heel.

reduce stimulation during gait; and (IV) wearing sandals or clogs $(1,10,12,14,15)$. Thus far, the effects of these shoe modifications have not been studied; thus, clinical trials evaluating the effectiveness of shoe modifications should be performed.

\section{Retrocalcaneal bursitis}

Retrocalcaneal bursitis is the most common form of heel bursitis, involving irritation from the shoes and painful inflammation (12). The retrocalcaneal bursa is located between the anteroinferior wall of the Achilles tendon and posterosuperior surface of the calcaneus (16). The anterior surface of the retrocalcaneal bursa is composed of fibrocartilage, the superior surface consists of adipose tissue, and the posterior surface merges with the paratenon of the anterior Achilles tendon $(16,17)$. Irritation of the retrocalcaneal bursa from poor-fitting shoes or overuse of the heel and ankle can induce retrocalcaneal bursitis. It frequently occurs with other disorders, including Haglund's deformity, rheumatoid arthritis, ankylosing spondylitis, psoriatic arthritis, Reiter's syndrome, pseudogout, and gout (18). Therefore, it is necessary to evaluate the coexistence of these disorders in affected patients.

The clinical features of retrocalcaneal bursitis include tenderness of the anterior Achilles tendon and pain in the posterior ankle with medial and lateral compression. Furthermore, erythema or swelling around the Achilles tendon can develop $(1,17)$. Conservative treatment includes rest, ice use, physical rehabilitation, anti-inflammatory/ analgesic medication, and shoe modification. Furthermore, corticosteroid injection in the retrocalcaneal bursa effectively decreases inflammation and relieves symptoms $(1,19,20)$. The most applicable shoe modification for patients with retrocalcaneal bursitis is to place a heel lift inside the shoe, which prevents contraction of the retrocalcaneal bursa with the shoe counter. Furthermore, loosening the shoe counter can help manage retrocalcaneal bursitis (12). However, clinical trials examining these shoe modifications are rare, and their clinical effectiveness should be investigated.

\section{Plantar fasciitis}

Plantar fasciitis, the most common cause of plantar heel pain, is a chronic degenerative process involving the plantar aponeurosis of the foot. It is common in both sedentary and athletic populations and has a lifetime prevalence of $10 \%$ in the general population. Plantar fasciitis typically presents with medial plantar heel pain during weight bearing, especially with the first steps in the morning. It frequently occurs in middle-aged women and is prevalent in longdistance runners, military servicemen, obese people, and individuals with a cavus or planus foot deformity (1,21-23). Furthermore, low-heeled shoes with solid soles or tightly fitting shoes can be aggravating factors (24). Disorders such as fat-pad atrophy, calcaneal stress fractures, and proximal plantar fibroma should be differentiated from plantar fasciitis $(24,25)$.

Conservative treatments for plantar fasciitis include rest, activity modification, stretching and strengthening exercises, shockwave therapy, glucocorticoid injection, antiinflammatory or analgesic medications, arch taping, and orthosis $(1,23,26)$.

Orthotic treatment methods are as follows: (I) heel cup: relieves tension by raising the patient's heel, providing an extra-cushioning effect and controlling supination and pronation; (II) soft heel pad: reduces pain by dispersing pressure; (III) navicular pad supporting the medial arch: relieves tension in the fascia; (IV) shoe internal or external medial heel wedge: prevents eversion and arch collapse; (V) Thomas heel (12-15-mm extension of the standard heel on the medial edge): reduces tension in the plantar fascia by supporting the arch (Figure 3); and (VI) night splint: reduces shortness in the plantar fascia by holding the foot in a neutral position during sleep (12,22,26-28).

In 2002, Gross et al. (29) investigated the effect of the use of a custom semirigid foot orthosis in 15 patients with plantar fasciitis for 12-17 days. The custom semirigid foot 


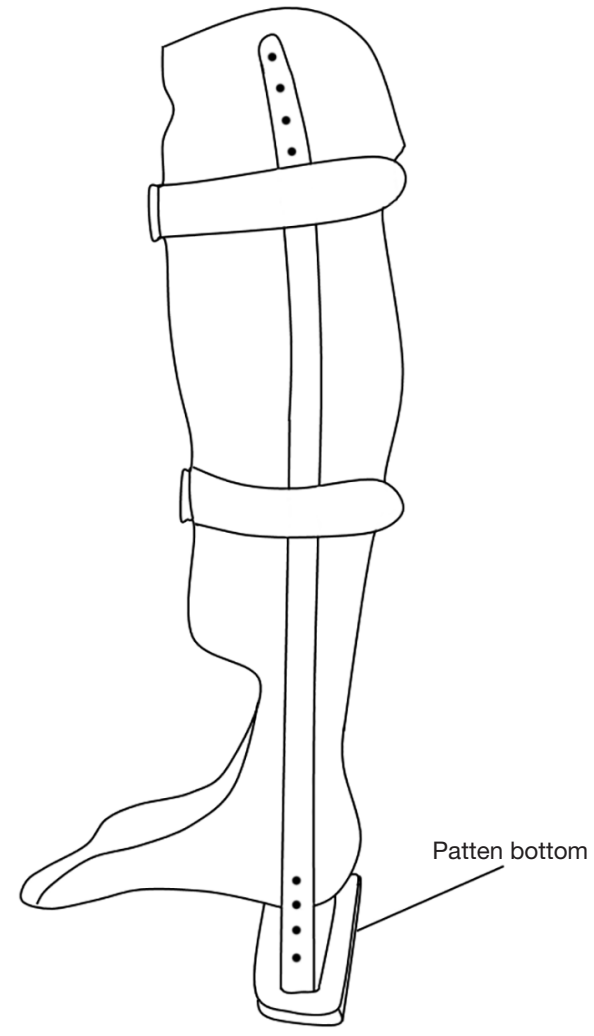

Figure 4 Patellar tendon-bearing orthosis with a patten bottom.

orthosis consisted of four layers for shock absorption and maintained the rearfoot in a neutral position. After applying the custom semirigid foot orthosis, pain was significantly reduced, and $66 \%$ of the initial pain was reduced. In 2015, Niazi et al. (30) evaluated the effect of silicone heel pads in 100 patients with plantar fasciitis; $84 \%$ of the included patients showed significant short-term pain relief. In 2019, Grim et al. (31) investigated the effect of a customized foot orthosis consisting of three cushion layers on the plantar fasciitis. In total, 63 patients with plantar fasciitis were recruited and allocated to manual therapy, customized foot orthosis, or combined therapy groups. All groups showed significant relief in the symptoms of plantar fasciitis.

\section{Calcaneal stress fracture}

Calcaneal stress fractures occur because of repetitive impact during heel strike and are particularly prevalent in runners $(1,32,33)$. Patients with calcaneal stress fractures can present with pain similar to that of plantar fasciitis; however, it is often distinguished by tenderness in the medial and lateral aspects of the calcaneal bone (21). When a calcaneal stress fracture is clinically suspected, imaging studies, such as $\mathrm{X}$-ray examination, computed tomography, and magnetic resonance imaging, can confirm the diagnosis (34).

The main treatment strategy for calcaneal stress fractures is to reduce the mechanical load on affected areas to facilitate natural healing (34). Although the treatment duration varies depending on fracture severity, the average treatment period is 6 weeks (35). To reduce the mechanical loading on the affected foot, patients are recommended to use crutches for non- or partial-weight-bearing activities and refrain from more intense activities. A cast can also effectively prevent mechanical loading on the affected foot $(32,34,35)$. Regarding applicable orthoses for calcaneal stress fractures, heel cushions or heel pads help absorb and disperse the shock to the calcaneal bone. The patellar tendon-bearing (PTB) orthosis can immobilize the foot joints and reduce overall peak plantar pressure loading on the foot $(36,37)$. Furthermore, adding a patten bottom to a PTB orthosis (Figure 4) can achieve non-weight bearing of the foot by avoiding contact with the floor (37). In 2015, Pfeifer et al. (35) investigated treatment methods for foot and ankle fractures at 213 institutions and reported that the majority of institutions recommended partial weightbearing for 6 weeks after the onset of fracture, preferring that the fractures are fixed to $10^{\circ}$ of plantar flexion.

\section{Heel fat pad atrophy}

The heel pad is composed of closely packed fat chambers surrounded by elastin fibers and tough circular or coneshaped collagenous septa (38). The heel fat pad absorbs shock on the heel, acting as a cushion. However, atrophic changes occur with aging. Heel fat pad atrophy is known to be the second most common cause of the plantar heel pain; $14.8 \%$ of cases of total plantar heel pain occur because of heel fat pad atrophy. Furthermore, rheumatoid disease or altered biomechanical alignment causes heel fat pad atrophy. When heel fat pad atrophy occurs, destruction of the fibrous membrane, loss of moisture content, and decreased elasticity of the soft tissue manifest in the heel fat pad, leading to reduced shock absorbing function of the heel fat pad (39).

The clinical features of heel fat pad atrophy include easy palpation of the calcaneus bone when pushing the plantar heel with the hand and aggravation of heel pain, especially when standing for a long period with bare feet or on a hard floor. Furthermore, there is tenderness in the plantar aspect of the calcaneus bone. Therefore, confirming heel 
fat pad atrophy using ultrasound can increase diagnostic accuracy $(21,39)$.

Conservative treatments for heel fat pad atrophy include rest, ice use, non-steroidal anti-inflammatory medications, and orthosis $(38,39)$. The applicable foot orthoses are (I) the heel rocker soled shoe; (II) the cushioned heel pad, which provides padding and support for the heel during walking and alleviates pain in the heel by reducing the pressure applied to the calcaneal area; and (III) the solid ankle cushion heel (SACH), composed of soft compressible material, which can reduce the impact during heel strike and help push off to improve gait more naturally $(12,26,39-42)$. However, the effectiveness of these orthoses in patients with heel fat pad atrophy has not been studied yet. Therefore, their effectiveness should be investigated to enable their wide application.

\section{Tarsal tunnel syndrome}

Tarsal tunnel syndrome is a painful foot condition caused by compression of the tibial nerve within the tarsal tunnel $(43,44)$. This syndrome is more prevalent in women than in men and is induced by various factors, such as poorly fitting shoes, trauma, tarsal coalition, anatomic-biomechanical abnormalities such as rearfoot valgus or varus, postoperative scarring, lower extremity edema, systemic inflammatory arthropathies, diabetes, tenosynovitis, perineural fibrosis, osteophytes, hypertrophic retinaculum, and neuroma (45). Although there are no specific diagnostic tests for tarsal tunnel syndrome, it can be diagnosed based on a detailed past history and clinical examinations, such as two-point discrimination or the Tinel test (45).

Patients with tarsal tunnel syndrome may experience a prickly or stinging pain or numbness in the post-medial ankle and heel after standing or activity, a burning sensation at night, or pain spreading to the distal toes. In addition, motor weakness of the toes may occur $(1,46)$. Conservative treatments for tarsal tunnel syndrome include the reduction of activity, ice use, physical therapy such as ultrasound or iontophoresis, neuromodulatory/anti-inflammatory medications, corticosteroid injections, and orthosis $(1,45)$. The symptoms can be improved if the movement of the ankle joint is restricted or the pressure applied to the tarsal tunnel is reduced (47). Orthotic treatments include: (I) wearing shoes that secure the ankle without compressing the tarsal tunnel, (II) using rigid rocker soles to decrease joint motion in the foot and pressure under the heel, (III) supporting the arch to prevent traction of the tibial nerve,
(IV) using the Thomas heel to prevent a medial weight shift by slightly supporting the medial arch, (V) using the SACH to compensate for the reduction in shock absorption and ankle motion during the heel strike, (VI) wearing a night splint to decrease stress on the tibial nerve within the tarsal tunnel of the foot, and (VII) maintaining a subtalar neutral position by applying a custom-made orthosis to prevent foot eversion $(12,45,48)$. However, clinical trials evaluating these orthotic treatment methods are extremely rare.

\section{Conclusions}

In clinical practice, rearfoot pain is a common complaint. Shoe modification or application of orthoses can help manage rearfoot pain. However, clinical evidence for these conservative treatment methods is insufficient. Therefore, more clinical studies should be conducted for active and wide application of these methods.

\section{Acknowledgments}

Funding: The present study was supported by a National Research Foundation of Korea grant funded by the Korean government (grant number NRF-2019R1F1A1061348).

\section{Footnote}

Reporting Checklist: The authors have completed the NARRATIVE REVIEW reporting checklist. Available at http://dx.doi.org/10.21037/apm-20-446

Conflict of Interest: All authors have completed the ICMJE uniform disclosure form (available at http://dx.doi. org/10.21037/apm-20-446). The authors have no conflicts of interest to declare.

Ethical Statement: The authors are accountable for all aspects of the work in ensuring that questions related to the accuracy or integrity of any part of the work are appropriately investigated and resolved.

Open Access Statement: This is an Open Access article distributed in accordance with the Creative Commons Attribution-NonCommercial-NoDerivs 4.0 International License (CC BY-NC-ND 4.0), which permits the noncommercial replication and distribution of the article with the strict proviso that no changes or edits are made and the original work is properly cited (including links to both the 
formal publication through the relevant DOI and the license). See: https://creativecommons.org/licenses/by-nc-nd/4.0/.

\section{References}

1. Tu P. Heel Pain: Diagnosis and Management. Am Fam Physician 2018;97:86-93.

2. Scott LA, Munteanu SE, Menz HB. Effectiveness of orthotic devices in the treatment of Achilles tendinopathy: a systematic review. Sports Med 2015;45:95-110.

3. Erroi D, Sigona M, Suarez T, et al. Conservative treatment for Insertional Achilles Tendinopathy: platelet-rich plasma and focused shock waves. A retrospective study. Muscles Ligaments Tendons J 2017;7:98-106.

4. Paoloni JA, Appleyard RC, Nelson J, et al. Topical glyceryl trinitrate treatment of chronic noninsertionalachilles tendinopathy. A randomized, double-blind, placebocontrolled trial. J Bone Joint Surg Am 2004;86:916-22.

5. Rabusin CL, Menz HB, McClelland JA, et al. Efficacy of heel lifts versus calf muscle eccentric exercise for midportion Achilles tendinopathy (the HEALTHY trial): study protocol for a randomised trial. J Foot Ankle Res 2019;12:20.

6. Sobhani S, Zwerver J, van den Heuvel E, et al. Rocker shoes reduce Achilles tendon load in running and walking in patients with chronic Achilles tendinopathy. J Sci Med Sport 2015;18:133-8.

7. Farris DJ, Buckeridge E, Trewartha G, et al. The effects of orthotic heel lifts on Achilles tendon force and strain during running J Appl Biomech 2012;28:511-9.

8. Petersen W, Welp R, Rosenbaum D. Chronic Achilles tendinopathy: a prospective randomized study comparing the therapeutic effect of eccentric training, the AirHeel brace, and a combination of both. Am J Sports Med 2007;35:1659-67.

9. Natarajan S, Narayanan VL. Haglund Deformity Surgical Resection by the Lateral Approach. Malays Orthop J 2015;9:1-3.

10. Sofka CM, Adler RS, Positano R, et al. Haglund's syndrome: diagnosis and treatment using sonography. HSS J 2006;2:27-9.

11. Vaishya R, Agarwal AK, Azizi AT, et al. Haglund's Syndrome: A Commonly Seen Mysterious Condition. Cureus 2016;8:e820.

12. Jung DY, Kim JH, Kang P, et al. Pedorthics. Koonja, Seoul, 2010.

13. Sundararajan PP, Wilde TS. Radiographic, clinical, and magnetic resonance imaging analysis ofinsertional Achilles tendinopathy. J Foot Ankle Surg 2014;53:147-51.

14. Kucuksen S, Karahan AY, Erol K. Haglund Syndrome with Pump Bump. Med Arch 2012;66:425-7.

15. Myerson CL, Shimozono Y, Kennedy JG. Haglund's Deformity and Chronic Achilles Tendonitis. Oper Tech Orthop 2018;28:104-9.

16. Pękala PA, Henry BM, Pękala JR, et al. The Achilles tendon and the retrocalcaneal bursa: An anatomical and radiological study. Bone Joint Res 2017;6:446-51.

17. Weinfeld SB. Achilles tendon disorders. Med Clin North Am 2014;98:331-8.

18. Goldenstein-Schainberg C, Homsi C, Rodrigues Pereira $\mathrm{RM}$, et al. Retrocalcaneal bursitis in juvenile chronic arthritis. Ann Rheum Dis 1992;51:1162-3.

19. Morelli V, James E. Achilles tendinopathy and tendon rupture: conservative versus surgical management. Prim Care 2004;31:1039-54, x.

20. Stephens MM. Haglund's deformity and retrocalcaneal bursitis. Orthop Clin North Am 1994;25:41-6.

21. Lee WC. Common Foot and Ankle Disorders for Primary Care Physician. J Korean Acad Fam Med 2005;26:127-37.

22. Nitin AM, Jitendra J. Plantar Fasciitis: A Review. Indian J Pain 2018;32:24-9.

23. Thompson JV, Saini SS, Reb CW, et al. Diagnosis and management of plantar fasciitis. J Am Osteopath Assoc 2014;114:900-6.

24. Han TR, Bang MS, Kang YG, et al. Rehabilitation Medicine 3rd. Koonja, Seoul, 2008.

25. Martin RL, Davenport TE, Reischl SF, et al. Heel painplantar fasciitis: revision 2014. J Orthop Sports Phys Ther 2014;44:A1-33.

26. Gutteck N, Schilde S, Delank KS. Pain on the Plantar Surface of the Foot. Dtsch Arztebl Int 2019;116:83-8.

27. Seligman DA, Dawson DR. Customized heel pads and soft orthotics to treat heel pain and plantar fasciitis. Arch Phys Med Rehabil 2003;84:1564-7.

28. Wapner KL, Sharkey PF. The use of night splints for treatment of recalcitrant plantar fasciitis. Foot Ankle 1991;12:135-7.

29. Gross MT, Byers JM, Krafft JL, et al. The impact of custom semirigid foot orthotics on pain and disability for individuals with plantar fasciitis. J Orthop Sports Phys Ther 2002;32:149-57.

30. Niazi NS, Khan Niazi SN, Khan Niazi KN, et al. Effect of the silicone heel pad on plantar fasciitis. J Pak Med Assoc 2015;65:S123-7.

31. Grim C, Kramer R, Engelhardt M, et al. Effectiveness of Manual Therapy, Customised Foot Orthoses and 
Combined Therapy in the Management of Plantar Fasciitis-a RCT. Sports (Basel) 2019;7:128.

32. Pegrum J, Dixit V, Padhiar N, et al. The pathophysiology, diagnosis, and management of foot stress fractures. Phys Sportsmed 2014;42:87-99.

33. Welck MJ, Hayes T, Pastides P, et al. Stress fractures of the foot and ankle. Injury 2017;48:1722-6.

34. Bianchi S, Luong DH. Stress Fractures of the Calcaneus Diagnosed by Sonography: Report of 8 Cases. J Ultrasound Med 2018;37:521-9.

35. Pfeifer CG, Grechenig S, Frankewycz B, et al. Analysis of 213 currently used rehabilitation protocols in foot and ankle fractures. Injury 2015;46 Suppl 4:S51-7.

36. Alimerzaloo F, Kashani RV, Saeedi H, et al. Patellar tendon bearing brace: combined effect of heel clearance and ankle status on foot plantar pressure. Prosthet Orthot Int 2014;38:34-8.

37. Trepman E, Donnelly P. Patellar tendon-bearing, pattenbottom caliper suspension orthosis in active Charcot arthropathy: crutch-free ambulation with no weight bearing in the foot. Foot Ankle Int 2002;23:335-9.

38. Allam AE, Chang KV. Plantar Heel Pain. StatPearls (Internet). Treasure Island (FL): StatPearls Publishing; 2019.

39. Chae YH, Kim JS, Kang Y, et al. Clinical and Biomechanical Effects of Low-Dye Taping and Figure-8

Cite this article as: Choo YJ, Park CH, Chang MC. Rearfoot disorders and conservative treatment: a narrative review. Ann Palliat Med 2020;9(5):3546-3552. doi: 10.21037/apm-20-446
Modification of Low-Dye Taping in Patients With Heel Pad Atrophy. Ann Rehabil Med 2018;42:222-8.

40. Jørgensen U, Bojsen-Møller F. Shock absorbency of factors in the shoe/heel interaction--with special focus on role of the heel pad. Foot Ankle 1989;9:294-9.

41. Snook GA, Chrisman OD. The management of subcalcaneal pain. Clin Orthop Relat Res 1972;82:163-8.

42. Wu WL, Rosenbaum D, Su FC. The effects of rocker sole and SACH heel on kinematics in gait. Med Eng Phys 2004;26:639-46.

43. Doneddu PE, Coraci D, Loreti C, et al. Tarsal tunnel syndrome: still more opinions than evidence. Status of the art. Neurol Sci 2017;38:1735-9.

44. Neary KC, Chang E, Kreulen C, et al. Tarsal Tunnel Syndrome Secondary to Accessory Musculature: A Case Report. Foot Ankle Spec 2019;12:549-54.

45. Kiel J, Kaiser K. Tarsal Tunnel Syndrome. StatPearls (Internet). Treasure Island (FL): StatPearls Publishing; 2020.

46. Hudes K. Conservative management of a case of tarsal tunnel syndrome. J Can Chiropr Assoc 2010;54:100-6.

47. Kim MJ, Ahn JH, Choi KY. Diagnosis and Treatment of Tarsal Tunnel Syndrome. J Korean Orthop Assoc 2017;52:291-7.

48. Mariano DP, Manuel CM, Pau G, et al. The tarsal tunnel syndrome. Fuß \& Sprunggelenk 2015;13:227-36. 